\title{
Volatile and Non-volatile Forms of Aroma Compounds in Tea Leaves and Their Changes due to Injury
}

\author{
Ryoyasu SAIJō and Tadakazu TAKEO \\ National Tea Research Institute, Kanaya, Haibara-gun, Shizuoka, Japan
}

Received November 8, 1972

\begin{abstract}
Fresh tea leaves were homogenized in a chloroform-methanol mixture $(1: 1, \mathrm{v} / \mathrm{v})$, and separated into chloroform-soluble and methanol-water-soluble fractions after addition of water. From the chloroform-soluble fraction, the volatile forms of the aroma compounds were obtained. The non-volatile forms of the aroma compounds were associated with the methanol-water-soluble fraction, and were converted to volatile forms by hydrolysis with dilute acid.

The amount of the aroma compounds in the free form, such as cis-3-pentenol, hexanol, cis-3-hexenol, trans-2-hexenol, linalool, linalool oxide (cis, 5-membered), linalool oxide (trans, 5-membered), linalool oxide (trans, 6-membered), linalool oxide (cis, 6-membered), nerol, geraniol, phenylmethanol, and 2-phenylethanol, markedly increased during black tea manufacture. However, those in the bound form, showed a slight decrease during the manufacture. The increases in the former were also brought about by maceration, or treatment of the tea leaves with monoiodoacetate or malonate.
\end{abstract}

More than 140 aroma compounds are found in tea leaves and black tea. ${ }^{1,2)}$ However, there is a few information concerning changes of aroma compounds during black tea manufacture. ${ }^{3,4)}$ In the previous papers we reported that some volatile carbonyl compounds were produced from amino acids by interaction with quinones formed from catechins, ${ }^{3,0}$ and that some were produced from fatty acids. ${ }^{7}$ Whether or not the important volatile alcohols of black tea, cis-3-hexenol (fresh green leaf odor) and linalool (lily-like aroma), are produced during black tea manufacture remains to be determined. On the other hand, it is known that bound terpene alcohols occur in the pyrophosphate and glucoside forms. ${ }^{8 \sim 12}$ However, only the volatile forms of aroma compounds in tea have been investigated previously. The present paper describes the presence of two types of aroma compounds in tea leaves, and quantitative changes in these compounds due to the process of black tea manufacture and other kinds of injuries.

\section{MATERIALS AND METHODS}

Preparation of volatile fractions. Young tea shoots, consisting of a bud and three leaves, were used. A hundred $\mathrm{g}$ of the shoots was homogenized with an amount of $800 \mathrm{ml}$ chloroform-methanol mixture $(1: 1$, $v / v),{ }^{1.3}$ and the homogenate was then filtered. Water was added to a concentration of $40 \%$ in the filtrate, and the mixture was centrifuged to effect a separation of chloroform-soluble and methanol-water-soluble fractions. The methanol-water-soluble fraction was mixed again with a small amount of chloroform and separated as before. The combined chloroform fractions were concentrated under reduced pressure below $35^{\circ} \mathrm{C}$, and the concentrate was subjected to steam distillation under reduced pressure at $50^{\circ} \mathrm{C}$. The aroma compounds were extracted from the distillate with diethyl ether and this extract was concentrated to $30 \sim$ $50 \mathrm{mg}$. The preparations were run in duplicate for the quantitative studies and the concentrated ether solution, corresponding to $10 \mathrm{~g}$ leaves, was analyzed by gas chromatography.

Gas chromatography and peak identification. A Hitachi Model K-53 gas chromatograph equipped with a flame ionization detector was used. Gas chromatographic conditions were as follows: column packing, 10\% Carbowax $20 \mathrm{M}$ on Diasolid L ( $60 \sim 80$ mesh); He flow rate, $30 \mathrm{ml} / \mathrm{min}$; column temperature program, $130^{\circ} \mathrm{C}$ to $240^{\circ} \mathrm{C}$ at the rate of $1^{\circ} \mathrm{C} / \mathrm{min}$; attenuation range of detector, $1 / 10$. The gas chromatographic analyses were carried out in duplicate and the amounts of aroma compounds were shown as the average peak area $\left(\mathrm{cm}^{2}\right)$ of 2 gas chromatograms. 
Peak were identified by using aroma compounds obtained from a large amount of the fermented leaves after comparing their infrared spectra with those of authentic compounds.

Acid hydrolysis of the methanot-water-soluble fraction. After the methanol-water-soluble fraction was lyophilized, the residue was hydrolyzed with $0.8 \mathrm{~N} \mathrm{HCl}$ at $377^{\prime \prime} \mathrm{C}$ for $3.0 \mathrm{~min} .{ }^{14,15}$ ) The solution was then made alkaline and extracted with petroleum ether (bp $40 \sim 60$ C)

\section{RESULTS}

Two forms of aroma compounds in tea leaves

The volatiles in the chloroform-soluble fraction were analyzed by gas chromato- graphy. The results are shown in Fig. 1. The chromatogram of Fig. 1-A showed the typical gas chromatographic pattern of aroma compounds from tea leaves.

On the other hand, the gas chromatogram of the petroleum ether extract of the methanolwater-soluble fraction showed only small peaks (Fig. 1-B), which were known to originate in condensed petroleum ether. After the methanol-water-soluble fraction was hydrolyzed by dilute acid, aroma was generated and the gas chromatogram of the petroleum ether extract showed new peaks (Fig. 1-C, crosshatched peaks). The distillate obtained from the hydrolyzed methanol-water-soluble frac-

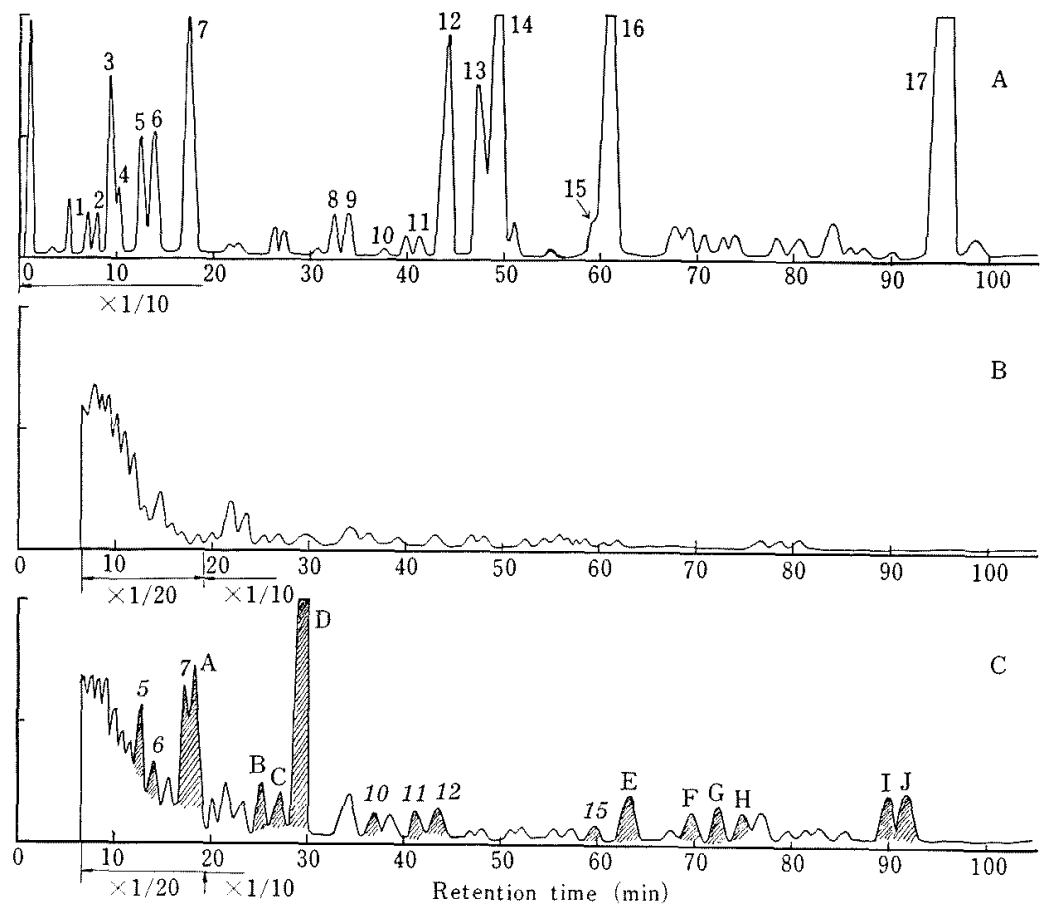

FIG. 1. Gas Chromatograms of the Volatile Fraction of the Chloroform-soluble Fraction (A), the Petroleum Ether Extract of the Methanol-water-soluble Fraction (B), and the Petroleum Ether Extract of Acid Hydrolyzed Methanol-water-soluble Fraction (C).

The clone used was Benihomare harvested in September. Identified peaks: 1, cis-2-pentenol; 2 , hexanol; 3, cis-3-hexenol; 4, trans-2-hexenol; 5, linalool oxide (cis, 5-membered); 6, linalool oxide (trans, 5-membered) 7, linalool; 8, linalool oxide (trans, 6-membered); 9, linalool oxide (cis, 6-membered); 10, nerol; 11, geraniol; 12, phenylmethanol; 13, 2-phenylethanol; 15, nerolidol $14,16,17$, unidentified. The volatile fraction corresponding to $10 \mathrm{~g}$ of original leaves was analyzed in the case of Fig. 1-A. Cross hatching in Fig. 1-C indicates the peaks derived by hydrolysis. The peaks of italics in Fig. 1-C are those that corresponded in retention times to the peaks in Fig. 1-A. The peaks in Fig. 1-B were recognized as those which orginated in condensed petroleum ether. 
tion also produced a similar gas chromatogram except for the absence of peaks coming from condensed petroleum ether. The peaks on the gas chromatogram of Fig. 1-C were not identified, but the retention times of several peaks corresponded to monoterpene alcohols in tea leaves.

From these results, it was evident that tea leaves contained two types of aroma compounds, i.e., the volatile form which was soluble in chloroform and the non-volatile form which was soluble in methanol-water and easily changed to the volatile form by dilute acid hydrolysis. Bound terpene alco- hols occur naturally in the pyrophosphate and glucoside forms. ${ }^{8 \sim 12}$ As both monoterpene pyrophosphate and glucoside are easily hydrolyzed by dilute acid, ${ }^{8,10,14,15}$ detailed experiments to determine the chemical structure of aroma compounds in the non-volatile form should be performed.

Increases of aroma compounds in the volatile form during the process of black tea manufacture

Quantitative changes of aroma compounds in the two forms during black tea manufacture and cold storage of fresh tea leaves are shown

Table I. Changes in Amounts of Aroma Compounds in the Volatile form during Black Tea Manufacture and Storage

Each figure indicates the peak area $\left(\mathrm{cm}^{2}\right)$ on gas chromatogram which is obtained from the concentrated ether solution, corresponding to $10 \mathrm{~g}$ fresh tea leaves, by the gas chromatographic condition described in the text.

\begin{tabular}{|c|c|c|c|c|c|}
\hline \multirow{2}{*}{$\begin{array}{l}\text { Peak } \\
\text { No. }\end{array}$} & \multirow[b]{2}{*}{ Aroma compound } & \multicolumn{3}{|c|}{ Stage of manufacture } & \multirow{2}{*}{$\begin{array}{l}\text { Stored } \\
\text { leaves }^{d}\end{array}$} \\
\hline & & $\begin{array}{l}\text { Fresh } \\
\text { leaves }\end{array}$ & $\begin{array}{l}\text { Withered } \\
\text { leaves }^{b}\end{array}$ & $\begin{array}{l}\text { Fermented } \\
\text { leaves }\end{array}$ & \\
\hline 1 & cis-2-Pentenol & 0.4 & 20.0 & 50.7 & 4.2 \\
\hline 2 & Hexanol & 0.2 & 89.0 & 24.0 & 3.3 \\
\hline 3 & cis-3-Hexenol & 7.6 & 146.0 & 79.0 & 1.9 \\
\hline 4 & trans-2-Hexenol & trace & 144.0 & 51.7 & 0.8 \\
\hline 5 & $\begin{array}{l}\text { Linalool oxide } \\
\text { (cis, 5-membered) }\end{array}$ & 6.8 & 53.5 & 115.0 & 4.7 \\
\hline 6 & $\begin{array}{l}\text { Linalool oxide } \\
\text { (trans, 5-membered) }\end{array}$ & 7.1 & 65.5 & 146.5 & 28.4 \\
\hline 7 & Linalool & 16.1 & 38.0 & 66.0 & 11.0 \\
\hline 8 & $\begin{array}{l}\text { Linalool oxide } \\
\text { (trans, 6-membered) }\end{array}$ & 9.2 & 37.0 & 42.3 & 12.2 \\
\hline 9 & $\begin{array}{l}\text { Linalool oxide } \\
\text { (cis, 6-membered) }\end{array}$ & 3.1 & 11.2 & 17.8 & 2.2 \\
\hline 10 & Nerol & 0.5 & 8.0 & 28.9 & 0.9 \\
\hline 11 & Geraniol & $\begin{array}{l}1.1 \\
(0.1 \mu \mathrm{g})^{e)}\end{array}$ & $\begin{array}{l}50.0 \\
(4.2 \mu \mathrm{g})\end{array}$ & $\begin{array}{l}227.5 \\
(18.9 \mu \mathrm{g})\end{array}$ & $\begin{array}{l}13.7 \\
(1.1 \mu \mathrm{g})\end{array}$ \\
\hline 12 & Phenylmethanol & 23.1 & 155.0 & 371.0 & 21.4 \\
\hline 13 & 2-Phenylethanol & 16.9 & 355.0 & 1540.0 & 52.2 \\
\hline 14 & Unidentified & 18.3 & 6.6 & trace & 10.3 \\
\hline 15 & Nerolidol & trace & trace & trace & 0 \\
\hline 16 & Unidentified & 89.0 & 125.0 & 60.0 & 56.0 \\
\hline 17 & Unidentified & 123.0 & 24.5 & 18.3 & 24.0 \\
\hline
\end{tabular}

a) The clone used was Benihomare harvested in September.

$b$; The leaves were allowed to wither on a net for $16 \mathrm{hr}$ at room temperature (average, $21^{\circ} \mathrm{C}$ ). The weight of withered leaves was $57 \%$ that of the original leaves.

c) The withered leaves were rolled for $1 \mathrm{hr}$ with a rolling machine and allowed to ferment for $1.5 \mathrm{hr}$ at room temperature $\left(23^{\circ} \mathrm{C}\right)$ after spreading to a depth of about $2 \mathrm{~cm}$.

d) The storage condition was at $5^{\circ} \mathrm{C}$ for 6 days in a polyethylene bag.

e) Calculated weight from the calibration curves of geraniol. 
Table II. Changes in Amounts of Aroma Compounds in the Non-volatile Form during Black Tea Manufacture and Storage

Each figure, ${ }^{a},{ }^{b},{ }^{c}$ ) and ${ }^{d /}$ are the same as in the legend of Table I.

\begin{tabular}{|c|c|c|c|c|c|}
\hline \multirow{2}{*}{$\begin{array}{l}\text { Peak } \\
\text { No. }\end{array}$} & \multirow{2}{*}{$\begin{array}{l}\text { Aroma compound } \\
\text { (tentatively) } \\
\text { identified }\end{array}$} & \multicolumn{3}{|c|}{ Stage of manufacture } & \multirow{2}{*}{$\begin{array}{l}\text { Stored } \\
\text { leaves }^{d}\end{array}$} \\
\hline & & $\begin{array}{l}\text { Fresh } \\
\text { leaves }^{a}\end{array}$ & $\begin{array}{l}\text { Withered } \\
\text { leaves }^{b 1}\end{array}$ & $\begin{array}{c}\text { Fermented } \\
\text { leaves }\end{array}$ & \\
\hline 5 & $\begin{array}{l}\text { Linalool oxide } \\
\text { (cis, 5-membered) }\end{array}$ & 5.6 & 5.3 & 7.5 & 6.3 \\
\hline 6 & $\begin{array}{l}\text { Linalool oxide } \\
\text { (trans, 5-membered) }\end{array}$ & 2.8 & 1.4 & 2.8 & 1.6 \\
\hline 7 & Linalool & 5.5 & 3.3 & 3.0 & 4.5 \\
\hline A & & 16.5 & 9.5 & 9.5 & 13.0 \\
\hline B & & 0.7 & 0.3 & trace & 0.5 \\
\hline $\mathrm{C}$ & & 2.1 & 2.0 & 2.0 & 2.3 \\
\hline $\mathrm{D}$ & & 54.0 & 26.6 & 11.4 & 38.5 \\
\hline 10 & Nerol & 0.2 & trace & trace & 0.1 \\
\hline 11 & Geraniol & 1.7 & 0.7 & 0.3 & 1.5 \\
\hline 12 & Phenylmethanol & 1.8 & 1.7 & 2.2 & 1.6 \\
\hline 15 & Nerolidol & 0.2 & trace & trace & trace \\
\hline $\mathrm{E}$ & & 0.3 & 0.1 & trace & trace \\
\hline $\mathrm{F}$ & & 7.0 & 3.2 & 3.8 & 4.5 \\
\hline $\mathrm{G}$ & & 6.2 & 4.8 & 4.3 & 7.9 \\
\hline $\mathbf{H}$ & & 0.6 & 0.7 & 1.1 & 0.7 \\
\hline I & Farnesol $(t, t)$ & 3.1 & 1.6 & 1.3 & 1.1 \\
\hline $\mathrm{J}$ & & 4.5 & 6.2 & 7.8 & 5.6 \\
\hline
\end{tabular}

in Tables I and II. From Table I, cis-2pentenol, hexanol, cis-3-hexenol, trans-2hexenol, linalool, linalool oxide (cis, 5-membered), linalool oxide (trans, 5-membered), linalool oxide (trans, 6-membered), linalool oxide (cis, 6-membered), nerol, geraniol, phenylmethanol, and 2-phenylethanol in the volatile forms markedly increased during the withering process, in which tea leaves were dehydrated. Moreover those compounds except hexanol, cis-3-hexenol and trans-2hexenol continued to increase during the fermentation process after grinding of the withered leaves. The increases of these compounds, however, were not observed during the storage of fresh tea leaves at $5^{\circ} \mathrm{C}$. Regarding aroma compounds in the nonvolatile form, several peaks showed a slight decrease during the process of black tea manufacture, as shown in Table II. The decreases are presumed to change their nonvolatile form to the volatile form. It is dif- ficult at present, however, to interprete the increases of aroma compounds in the volatile form during the process of black tea manufacture by the liberation of aroma compounds from the non-volatile form, since the aroma decreases in the non-volatile form are too small to the aroma increases in the volatile form.

Increases of aroma compounds in the volatile form by mechanical and chemical injuries

When fresh tea leaves were ground at once by a mortar machine (mechanical injury), or they were treated with chemicals (monoiodoacetate, malonate) for 2 days (chemical injury), the aroma compounds in the volatile form increased in injured tissues, as shown in Table III.

Therefore, the increases of these compounds were found to be due to not only the process of black tea manufacture, but also general injury to the leaves. 
Table III. Changes in Amounts of Aroma Compounds in the Volatile Form by Various Treatments

Each figure is the same as in the legend of Table 1.

\begin{tabular}{|c|c|c|c|c|c|}
\hline \multirow{2}{*}{$\begin{array}{l}\text { Aroma } \\
\text { compound }\end{array}$} & \multirow{2}{*}{$\begin{array}{c}\text { Fresh } \\
\text { leaves }^{a} \text { ) }\end{array}$} & \multirow{2}{*}{$\begin{array}{l}\text { Normally } \\
\text { fermented } \\
\text { leaves }^{b /}\end{array}$} & \multirow{2}{*}{$\begin{array}{l}\text { Mechanically } \\
\text { injured } \\
\text { leaves }\end{array}$} & \multicolumn{2}{|c|}{$\begin{array}{l}\text { Chemically } \\
\text { injured leaves }\end{array}$} \\
\hline & & & & $\begin{array}{l}\text { Monoiodo- } \\
\text { acetate }\end{array}$ & Malonate \\
\hline cis-2-Pentenol & 1.0 & 29.3 & 9.7 & 5.0 & 3.5 \\
\hline Hexanol & trace & 43.1 & 8.7 & 22.7 & 5.4 \\
\hline cis-3-Hexenol & 6.3 & 220.5 & 51.0 & 18.9 & 6.3 \\
\hline trans-2-Hexenol & 0.2 & 94.7 & 2.0 & 1.1 & 0.5 \\
\hline $\begin{array}{l}\text { Linalool oxide } \\
\text { (cis, 5-membered) }\end{array}$ & 2.8 & 126.0 & 72.0 & 61,0 & 37.5 \\
\hline Linalool oxide & 7.7 & 312.0 & 231.0 & 136.0 & 108.0 \\
\hline $\begin{array}{l}\text { (trans, 5-membered) } \\
\text { Linalool }\end{array}$ & 10.8 & 95.6 & 49.0 & 23.4 & 11.7 \\
\hline $\begin{array}{l}\text { Linalool oxide } \\
\text { (trans, 6-membered) }\end{array}$ & 1.7 & 12.8 & 16.8 & 12.8 & 8.8 \\
\hline $\begin{array}{l}\text { Linalool oxide } \\
\text { (cis, 6-membered) }\end{array}$ & 14.2 & 41.7 & 61.4 & 35.7 & 24.3 \\
\hline Nerol & 0.6 & 8.0 & 20.2 & 2.7 & 1.8 \\
\hline Geraniol & $\begin{array}{l}5.9 \\
(0.5 \mu \mathrm{g})\end{array}$ & $\begin{array}{l}215.6 \\
(17.9 \mu \mathrm{g})\end{array}$ & $\begin{array}{l}155.8 \\
(12.9 \mu \mathrm{g})\end{array}$ & $\begin{array}{l}33.2 \\
(2.8 \mu \mathrm{g})\end{array}$ & $\begin{array}{l}23.5 \\
(2.0 \mu \mathrm{g})\end{array}$ \\
\hline Phenylmethanol & 14.1 & 197.5 & 495.0 & 59.7 & 33.0 \\
\hline 2-Phenylethanol & 37.5 & 891.0 & 1106.0 & 126.8 & 109.3 \\
\hline Nerolidol & 5.2 & .9 .0 & 4.2 & trace & trace \\
\hline
\end{tabular}

a) The clone used was Benifui harvested in October.

b) The leaves were withered for $16.5 \mathrm{hr}$, rolled for $1.0 \mathrm{hr}$, and fermented for $1.5 \mathrm{hr}$ at room temperature (average, $17^{\circ} \mathrm{C}$ ).

c) The leaves were macerated for $1.5 \mathrm{hr}$ by using a mortar machine and allowed to ferment after spreading to a depth of about $2 \mathrm{~cm}$.

d) $10^{-2} \mathrm{M}$ Monoiodoacetate (or $10^{-1} \mathrm{M}$ malonate) solution was absorbed from stem into the leaves under fluorescent light and wind produced by a fan. During 2 days absorption, the leaves gradually changed in color from green to brown.

Time course of aroma compounds in the volatile form after maceration

Changes in the amounts of aroma compounds in the volatile form after maceration were investigated for $5 \mathrm{hr}$. The results are shown in Fig. 2. cis-2-Pentenol, hexanol, cis-3-hexenol, and linalool increased markedly at the earlier stage after maceration, followed by a slight decrease. Linalool oxide (cis, 5-membered), linalool oxide (trans, 5-membered), geraniol, phenylmethanol, and 2phenylethanol continued to increase during the period tested. The gradual increases of linalool oxide (cis, 5-membered) and linalool oxide (trans, 5-membered) were assumed to arise from the conversion of linalool.

\section{DISCUSSION}

It has not been reported the observation that aroma compounds in the non-volatile form are present in tea leaves and that the amounts of aroma compounds in the volatile form markedly increase during the process of black tea manufacture. The latter observation was different from the previous results, i.e., some of them did not change and some decreased slightly during rolling and fermentation processes. As the different results were estimated to be due to the different methods of preparation for aroma compounds, the two methods were compared. 

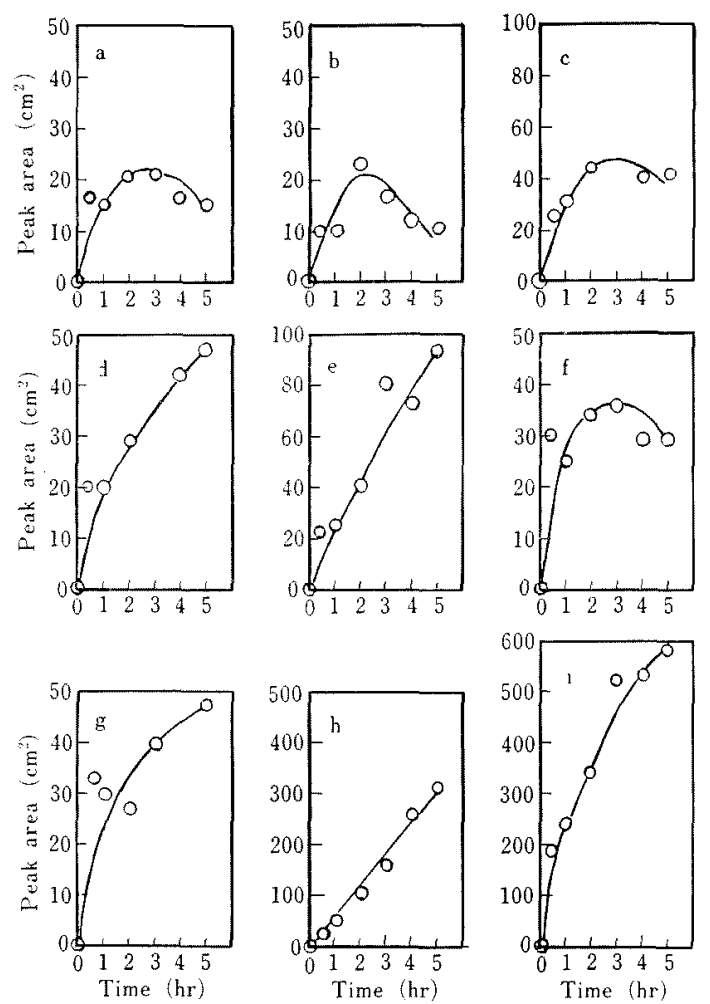

FIG. 2. Time Course of the Increases of Aroma Compounds in the Free Form in Tea Leaves after Maceration.

The clone used was Benifuji harvested in February. Tea leaves were macerated for $0.5 \mathrm{hr}$ by using a mortar machine at room temperature $\left(6^{\circ} \mathrm{C}\right)$, and then allowed to undergo fermentation at $12^{\circ} \mathrm{C}$. Peak area is the same as in the legend of Table $\mathrm{I}$.

a, cis-2-pentenol; b, hexanol; c, cis-3-hexenol; d, linalool oxide (cis, 5-membered); e, linalool oxide (trans, 5-membered); f, linalool; g, geraniol; h, phenylmethanol; i, 2-phenylethanol. In the leaves only a small amount of trans-2-hexenol was detected, but linalool oxide (trans, 6-membered), linalool oxide (cis, 6-membered) nerol, and nerolidol were not detected.

The aroma compounds in the volatile form were prepared from fresh tea leaves of the clone Yabukita by the present method and the previous method, ${ }^{4 *}$ and analyzed by gas

* Preparation was carried out as follow. The shoots were immersed for $24 \mathrm{hr}$ at room temperature in three portions of ether, thereafter the ether was separated. This procedure was repeated three times and the total ether solution was subjected to the same procedure of the chloroform fraction in the present method. chromatography. The result as shown in Table IV indicates that 2 unidentified aroma compounds are found in a larger amount in the present method than in the previous

\section{Table IV. Comparison in Amounts of Aroma COMPOUNDS IN THE Volatile Form Prepared From Two METHODS}

Each figure is the same as in the legend of Table 1. The clone used was Yabukita harvested in August.

\begin{tabular}{lcc}
\hline \multicolumn{1}{c}{ Aroma compound } & $\begin{array}{c}\text { Present } \\
\text { method }\end{array}$ & $\begin{array}{c}\text { Previous } \\
\text { method }\end{array}$ \\
\hline Hexanal & trace & 1.0 \\
trans-2-Hexenal & 0.4 & 1.1 \\
cis-2-Pentenol & 0.2 & 4.6 \\
Hexanol & trace & 1.2 \\
cis-3-Hexenol & 9.5 & 28.6 \\
trans-2-Hexenol & trace & trace \\
Linalool oxide & 1.1 & 8.9 \\
$\quad$ (cis, 5-membered) & & \\
Linalool oxide & 2.5 & 17.3 \\
$\quad$ trans, 5-membered) & & \\
Linalool & 8.5 & 48.7 \\
Linalool oxide & 0.7 & 4.4 \\
$\quad$ trans, 6-membered) & & \\
Linalool oxide & 2.7 & 4.0 \\
$\quad$ cis, 6-membered) & & \\
Nerol & trace & trace \\
Geraniol & 0.8 & 33.0 \\
Phenylmethanol & 1.3 & 76.5 \\
2-Phenylethanol & 0.6 & 19.8 \\
Unidentified & 12.1 & trace \\
Nerolidol & 4.3 & 4.3 \\
Unidentified & 10.7 & 0 \\
\hline & & \\
& &
\end{tabular}

method, while the other compounds except trans-2-hexenol and nerol are found in a larger amount in the previous method than in the present method. From these results, gas chromatographic pattern of fresh tea leaves obtained from the previous method seems similar to that of withered or fermented leaves shown in Table I. Compared two methods, the efficiency of extraction by the present method is not less inferior than that by the previous method because of its extraction with maceration, furthermore aroma changes during the extraction period by the present method is less than those by the previous method because of its shorter time of extraction. Therefore, gas chromatographic 
pattern of fresh tea leaves in the previous method might be slightly changed. So we consider that original contents of aroma compounds in fresh tea leaves is more correctly exhibited on the gas chromatographic pattern of the present method than that of the previous method.

Since it has been revealed the fact that aroma compounds in the free form increase markedly due to various kinds of injuries tested in the experiments, the origins of the aroma compounds in the volatile form and the mechanisms concerning these increases become problems to be solved.

Acknowledgement. We express our thanks to Dr. James E. Baker of the Agricultural Research Service, U.S. Department of Agriculture, for his kind assistance in the preparation of this manuscript.

\section{REFERENCES}

1) T. Yamanishi, Eiyo to shokuryo, 43, 227 (1968) (in Japanese)
2) S. Sato, S. Sakakura, A. Kobayashi, Y. Nakatani and T. Yamanishi, Agr. Biol. Chem., 34, 1355 (1970).

3) T. Yamanishi, A. Kobayashi, H. Sato, H. Nakamura, K. Osawa, A. Uchida, S. Mori and R. Saijō ibid., 30, 784 (1966).

4) R. Saijō and Y. Kuwabara, ibid., 31, 389 (1967).

5) R. Saijō and T. Takeo, ibid., 34, 222 (1970).

6) R. Saijö and T. Takeo, ibid., 34, 227 (1970).

7) R. Saijō and T. Takeo, Plant \& Cell Physiol., 13, 991 (1972).

8) E. Beytia, P. Valenzuela and O. Cori, Arch. Biochem. Biophys., 129, 346 (1969).

9) O. Cori, Arch. Biochem. Biophys., 135, 416 (1969).

10) M. J. O. Francis and C. Allcock, Phytochem., 8, 1339 (1969).

11) J. Grimshaw, Chem. \& Ind., 403 (1961),

12) H. Inouye, $S$. Inouye, $N$. Shimokawa und $M$. Okigawa, Tetrahedron Letters, 6, 683 (1968).

13) J. Folch, M. Lees and G. H. Stanley, J. Biol. Chem., 226, 497 (1957).

14) J. K. Dorsey, J. A. Dorsey and J. W. Porter, J. Biol. Chem., 241, 5353 (1966).

15) C. Donninger and G. Popjak, Biochem. J., 105, 545 (1967). 